\title{
Gamma band oscillations in parietooccipital areas during performance of a sensorimotor integration task
}

\author{
A qEEG coherence study
}

\author{
Silmar Teixeira', Bruna Velasques, ${ }^{1,7}$, Sergio Machado ${ }^{1,7}$, \\ Flávia Paes ${ }^{9,10}$, Marlo Cunha ${ }^{1,7,8}$, Henning Budde ${ }^{6}$, Renato Anghinah², \\ Luis F.H. Basile ${ }^{2,3}$, Mauricio Cagy', Roberto Piedade', Pedro Ribeiro 1,4,7
}

\begin{abstract}
This study aimed to elucidate cortical mechanisms involved in anticipatory actions when 23 healthy right-handed subjects had to catch a free falling object through quantitative electroencephalogram ( $\mathrm{gEEG}$ ). For this reason, we used coherence that represents a measurement of linear covariation between two signals in the frequency domain. In addition, we investigated gamma-band $(30-100 \mathrm{~Hz})$ activity that is related to cognitive and somatosensory processes. We hypothesized that gamma coherence will be increase in both parietal and occipital areas during moment after ball drop, due to their involvement in manipulation of objects, visuospatial processing, visual perception, stimuli identification and attention processes. We confirmed our hypothesis, an increase in gamma coherence on P3-P4 ( $t=-2.15 ; p=0.033)$ and PZ-OZ ( $t=-2.16 ; p=0.034)$ electrode pairs was verified for a paired t-test. We conclude that to execute tasks involving anticipatory movements (feedforward mechanisms), like our own task, probably, there is no need of a strong participation of visual areas in the process of information organization to manipulate objects and to process visuospatial information regarding the contact hand-object.
\end{abstract}

Key words: catching, coherence, gamma, qEEG, sensorimotor integration.

Oscilações na banda gama em áreas parieto-occipitais durante desempenho de uma tarefa sensório-motora: um estudo de coerência na EEGq

\section{RESUMO}

Este estudo teve como objetivo elucidar os mecanismos corticais envolvidos em ações antecipatórias quando 23 indivíduos saudáveis destros tinham que apreender um objeto em queda livre, através da eletroencefalografia quantitativa (EEGq). Por esta razão, usamos a coerência que representa a covariação linear entre dois sinais no domínio da frequência. Além disso, investigamos a atividade da banda gama $(30-100 \mathrm{~Hz})$, que está relacionada à processos cognitivos e somato-sensoriais. Nossa hipótese é que a coerência de gama estará aumentada em ambas as áreas parietais e occipitais durante o momento pós-queda da bola, devido ao seu envolvimento na manipulação de objetos,

\section{Correspondence}

Sergio Machado

Rua Professor Sabóia Ribeiro 69 / apto 104 22430-130 Rio de Janeiro RJ - Brasil

E-mail: secm80@yahoo.com.br

Received 13 August 2010

Received in final form 1 November 2010 Accepted 11 November 2010
${ }^{1}$ Brain Mapping and Sensory Motor Integration, Institute of Psychiatry of Federal University of Rio de Janeiro (IPUB/UFRJ), Rio de Janeiro RJ, Brazil; '2Division of Neurosurgery, University of São Paulo Medical School, São Paulo SP, Brazil; ${ }^{3}$ Laboratory of Psychophysiology, UMESP, São Paulo SP, Brazil; ${ }^{4}$ School of Physical Education, Bioscience Department (EEFD/UFRJ), Rio de Janeiro RJ, Brazil; ${ }^{5}$ Division of Epidemiology and Biostatistics, Institute of Health Community, Federal Fluminense University (UFF), Rio de Janeiro RJ, Brazil; ${ }^{6}$ Department of Training - and Movement Sciences, Institute of Sportscience, Humboldt Universität zu Berlin, Germany; ${ }^{7}$ Institute of Applied Neuroscience (INA), Rio de Janeiro RJ, Brazil; ${ }^{8}$ Collegiate of Physical Education Course, Federal University of Vale do São Francisco (UNIVASF), Petrolina PE, Brazil, ${ }^{9}$ Panic and Respiration Laboratory, Institute of Psychiatry, Federal University of Rio de Janeiro, Rio de Janeiro RJ, Brazil; ${ }^{10}$ Faculty of Psychology, Brazilian Institute of Medicine and Rehabilitation (IBMR), Rio de Janeiro RJ, Brazil. 
processamento visuo-espacial, percepção visual, identificação de estímulos e processos de atenção. Confirmamos nossa hipótese. Um aumento de coerência em gama nos pares de eletrodos P3-P4 ( $t=-2,15 ; p=0,033)$ e PZ-OZ ( $t=-2,16 ; p=0,034)$ foi verificado por teste-t pareado. Conclui-se que, para executar tarefas que envolvem movimentos de antecipação (mecanismos de retro-alimentação) como a nossa própria tarefa, provavelmente, não há necessidade de forte participação de áreas visuais no processo de organização da informação como para manipular objetos e processar a informação visuo-espacial no contato mão-objeto.

Palavras-chave: apreensão, coerência, EEGq, gama, integração sensório-motora.

Over the last few years, neuroscientists have been extensively used qEEG as a valuable tool in the development of new avenues to tackle crucial issues in human motor control, especially in eye-guided hand movements $^{1,2}$. In face of this, eye-hand coordination is the control of eye movement with hand movement, and the processing of visual input to guide reaching and grasping along with the use of proprioception of the hands to guide the eyes ${ }^{3}$. Studies have shown that eyes generally direct the movement of the hands to targets ${ }^{4}$. Furthermore, the eyes provide initial information related to the object, such as size, shape and possibly grasping sites which are used to determine the force needed to be exerted by the fingertips for engaging in a given task, e.g., catching an object. For shorter tasks, the eyes often shift onto another task in order to provide additional input for planning further movements. On the other hand, for more precise movements or longer duration movements, continued visual input is used to adjust for errors in movement and to create more precise movements ${ }^{5}$.

In agreement with the relevance of this issue, the investigation of neural control of eye-hand coordination is complex because it involves several parts of the central nervous system (CNS) involved in vision, eye movements, touch, and hand control ${ }^{3,6,7}$, e.g., parietal and occipital regions. Both of these areas are believed to play a key role in eye-hand coordination during tasks. A more specific area, the parieto-occipital junction, is believed to be involved in the transformation of peripheral visual input for reaching with the hands, as observed in fMRI studies $^{8}$. Parieto-occipital junction particularly has been shown to have subdivisions for reaching and grasping actions. Moreover, the parietal region is believed to play an important role in relating proprioception and the transformation of motor sensory input to plan and control movement with regards to visual input ${ }^{9}$. It is a region responsible for providing relevant information about how occurs the integration of sensorimotor information, for instance, to catch an object (i.e., a ball) in free fall. It is known that parietal cortex had been demonstrating an important role during performance of tasks involving integration of visual and proprioceptive inputs from dif- ferent modalities ${ }^{10}$, manipulation of objects, and visuospatial processing ${ }^{6,11}$. Finally, visual cortex is responsible for visual perception, stimuli identification and attention processes, mainly in dynamic environment involving objects detection which demands a high readiness state ${ }^{12}$.

This paradigm allows analyzing the relation among cortical regions during certain processes, such as spatial attention and readiness when subjects have to perform a motor act ${ }^{13}$, specifically, when shifts in coordination of visuospatial and somatosensory inputs for task execution (i.e., moment after ball drop) are requested ${ }^{6,10,11}$. Catching an object is a complex movement which involves not only programming but also effective motor coordination. Such behavior is related to the activation and recruitment of cortical regions which participates in the sensorimotor integration process that gathers information coming from the environment and the performed motor task in order to prepare motor acts and to enhance the execution of goal-directed tasks ${ }^{14-16}$, e.g., catching an object. Thus, the cortical areas are recruited to promote a self-organization (i.e., the functional reorganization of circuits) of neural networks for the constitution of a functional group (binding problems) ${ }^{17}$ to improve the coordination and the motor control due to the instability induced by the task ${ }^{14-16}$.

Based on this assumption, our experiment investigated the coherence of the quantitative electroencephalogram (qEEG) in parietal and occipital regions in a catching task when participants have to catch a ball in free fall. Coherence represents a measurement of linear covariation between two signals in the frequency domain. In addition, we investigated gamma band (30-100 $\mathrm{Hz}$ ) that has been related to cognitive process, memory, and spatial/temporal and proprioceptive integration factors, e.g. attention selection and stimulus encoding ${ }^{18-20}$. From a physiological perspective, there are strong arguments for synchronization in the gamma-band being important for neuronal communication. If a neuron receives input from several other neurons, this drive is enhanced if the spiking inputs are coincident because the synchronization enables the postsynaptic potentials with short duration, e.g., $\sim 10 \mathrm{~ms}$, which defines the timeframe 
of temporal integration, resulting in a 'tighter' synchronization of gamma-frequency oscillations ${ }^{18,20}$.

Several laboratories have reported an increase in amplitude of gamma-spectrum during sensory and cognitive processes ${ }^{17-20}$. Particularly, our study observed the coupling among cortical areas in gamma coherence. Contrary to other experiments ${ }^{21,22}$, our group explored the relevant role of gamma expressing cortical coupling among different regions. Therefore, this study aimed at trying to elucidate electrocortical mechanisms involved in anticipatory actions when individuals had to catch a free falling object (i.e., ball) through qEEG. Our hypothesis is that an increase in gamma coherence for both areas will be observed during the moment after ball drop, due to their involvement in manipulation of objects, and visuospatial processing (e.g., spatiotemporal coordination related to the contact hand-object) $)^{10,11}$ and visual perception, stimuli identification and attention processes, mainly in dynamic environment involving objects detection which demands a high readiness state ${ }^{12}$.

\section{METHOD}

\section{Sample}

Sample was composed of 23 healthy subjects (13 male and 10 female), right handed ${ }^{23}$, with ages varying between 25 and 40 years old (mean: 32.5, SD: 7.5). Inclusion criteria were absence of mental or physical impairments, no history of psychoactive substances and no neuromuscular disorders (screened by a previous anamnesis and clinical examination). All subjects signed a consent form and were aware of the whole experimental protocol. The experiment was approved by the Ethics Committee of Federal University of Rio de Janeiro (IPUB/UFRJ). This experimental paradigm has been already used in other experiment ${ }^{14-16}$.

\section{Task procedures}

The task was performed in a sound and light-attenuated room, to minimize sensory interference. Individuals sat on a comfortable chair to minimize muscular artifacts, while electroencephalography and electromyography (EMG) data were collected. An electromagnetic system, composed of two solenoids, was placed right in front of the subject and released 8-cm balls, one at each $11 \mathrm{~s}$, at $40 \mathrm{~cm}$ above the floor, straight onto the subject's hand. The right hand was placed in a way that the four medial metacarpi were in the fall line. After its catch, the ball was immediately discharged. Each released ball composed a trial and blocks were made of 15 trials. All experiment had six blocks that lasted 2 min and 30s with 1 min intervals between them.

\section{Data acquisition}

Electroencephalography - The International 10/20
System for electrodes ${ }^{24}$ was used with the 20-channel EEG system Braintech-3000 (EMSA-Medical Instruments, Brazil). The 20 electrodes were arranged in a nylon cap (ElectroCap Inc., Fairfax, VA, USA) yielding monopole derivations referred to linked earlobes. In addition, two 9-mm diameter electrodes were attached above and on the external corner of the right eye, in a bipolar electrode montage, for eye-movement (EOG) artifacts monitoring. Impedance of EEG and EOG electrodes were kept under 5-10 K $\Omega$. The data acquired had total amplitude of less than $100 \mu \mathrm{V}$. The EEG signal was amplified with a gain of 22,000, analogically filtered between $0.01 \mathrm{~Hz}$ (high-pass) and $100 \mathrm{~Hz}$ (lowpass), and sampled at 240 Hz. The software Data Acquisition (Delphi 5.0), developed at the Brain Mapping and Sensorimotor Integration Laboratory was employed to filter the raw data: notch $(60 \mathrm{~Hz})$, high-pass of $0.3 \mathrm{~Hz}$ and low-pass of $100 \mathrm{~Hz}$.

Electromyography - Electromyographic (EMG) activity of the flexor carpi radialis (FCR), flexor carpi ulnaris (FCU), extensor carpi radialis (ECR) and extensor carpi ulnaris (ECU) was recorded by an EMG device (LynxEMG1000), to monitor and assess any voluntary movement during the task. Bipolar electrodes $(2 \mathrm{~mm}$ recording diameter) were attached to the skin. The reference electrode was fixed on the skin overlying the lateral epicondyle near the wrist joint. The skin was cleaned with alcohol prior to electrode attachment. The EMG was amplified $(\times 1000)$, filtered $(10-3000 \mathrm{~Hz})$, digitized (10000 samples/s), and recorded synchronously to the EEG onto the computer's hard drive. In each trial, the EMG signal was rectified and averaged over $500 \mathrm{~ms}$ from the trigger point.

\section{Data processing}

To quantify reference-free data, a visual inspection and independent component analysis (ICA) were applied to identify and remove any remaining artifacts, i.e., eye blinks and ocular movements produced by the task. Data from individual electrodes exhibiting loss of contact with the scalp or high impedances $(>10 \mathrm{k} \Omega$ ) were deleted and data from single-trial epochs exhibiting excessive movement artifact $( \pm 100 \mu \mathrm{V})$ were also deleted. Independent component analysis (ICA) was then applied to identify and remove any remaining artifacts after the initial visual inspection. ICA is an information maximization algorithm that derives spatial filters by blind source separation of the EEG signals into temporally independent and spatially fixed components. Independent components resembling eye-blink or muscle artifact were removed and the remaining components were then back-projected onto the scalp electrodes by multiplying the input data by the inverse matrix of the spatial filter coefficients derived from ICA using established procedures. The ICAfiltered data were then reinspected for residual artifacts 
using the same rejection criteria described above. Then, a classic estimator was applied for the power spectral density (PSD), or directly from the square modulus of the FT (Fourier Transform), which was performed by MATLAB (Matworks, Inc.). Quantitative EEG parameters were reduced to 4-s periods (the selected epoch started $2 \mathrm{~s}$ before and ended $2 \mathrm{~s}$ after the trigger, i.e., moment preceding balls drop and moment after balls drop). The electrophysiological measure analyzed was coherence. It represents a measurement of linear covariation between two signals in the frequency domain. It is mathematically bounded between zero and one, whereby one signifies a perfect linear association and zero denotes that the signals are not linearly related at that particular frequency. The premise is that when activities from spatially remote events covary they tend to interact, also denoted as functional connectivity. Standard coherence as a measure of functional coupling provides a link between two signals but no directional information. To this end, estimators can be constructed, such as a directed transfer function, which examines asymmetries in inter-regional information flow and establishes a direction of drive between the coupled sites ${ }^{25,26}$.

\section{Statistical analysis}

The statistical design allowed for examination of functional connectivity and directionality of the communication between the sensorimotor areas in each hemisphere, with respective regions related to sensory, motor execution, and integrative or associative functions. All results are given as mean values and standard deviation. A paired t-test was used to analyze the within subject's factor moment (i.e., preceding and after ball drop) for each pair of electrodes: P3-P4, P3-PZ, P4-PZ, O1-O2, O1-OZ, O2-OZ, P3-O1, P4-O2, OZ-PZ. Moreover, we used the Bonferroni correction to address the problem of multiple comparisons. The outcome of statistical calculations were declared significant if $\mathrm{p}<0.05$. For statistical analysis SPSS package was used.

\section{RESULTS}

The first statistical analysis with regard to frontal region demonstrated a significant difference in P3/P4 electrodes pair $(\mathrm{t}=-2.15 ; \mathrm{p}=0.033)$. It was found a significant increase in the gamma coherence when compared the moments preceding (mean $=0.52 ; \mathrm{SD}=0.079$ ) and after (mean=0.54; SD=0.087) ball drop as observed in Fig 1. The second analysis verified a significant difference in $\mathrm{PZ} / \mathrm{OZ}$ electrodes pair $(\mathrm{t}=-2.16 ; \mathrm{p}=0.034)$. It was observed an increase in the gamma coherence when compared the moment preceding (mean $=0.58 ; \mathrm{SD}=0.074$ ) and after (mean=0.59; SD $=0.078$ ) ball drop as observed in Fig 2.

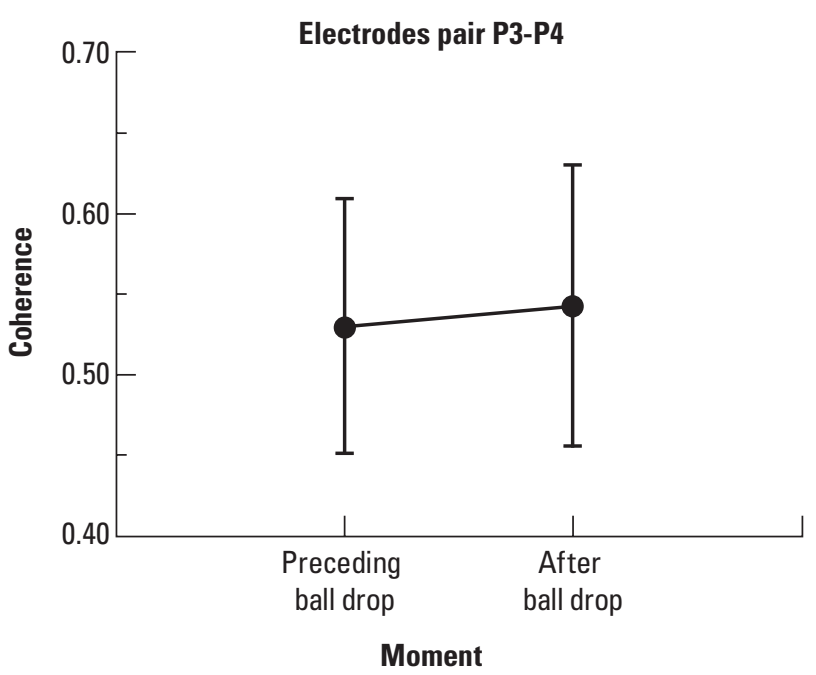

Fig 1. Mean and standard deviation for coherence on gamma band. Significant different between moments observed by t-test $(p<0.033)$.

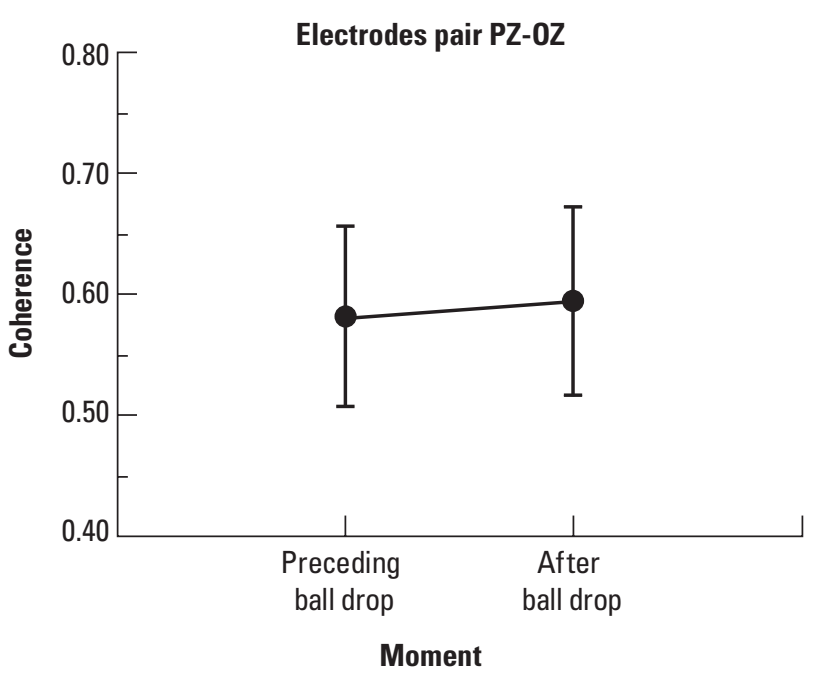

Fig 2. Mean and standard deviation for coherence on gamma band. Significant different between moments observed by t-test $(p<0.034)$.

\section{DISCUSSION}

The current experiment is an attempt to elucidate electrocortical mechanisms regarding anticipatory actions involved in voluntary movements. In particular, subjects had to catch a free falling object (i.e., ball). Our hypothesis is that an increase in gamma coherence for both areas will be observed during moment after ball drop, due to their involvement in manipulation of objects, and visuospatial processing (e.g., spatiotemporal coordination related to the contact hand-object) $)^{10,11}$ and visual perception, stimuli identification and attention processes, mainly in dynamic environment involving objects detection which demands a high state of alert ${ }^{12}$. 
Gamma-band represents a large scale approach to study sensorimotor integration mechanisms in association with binding ${ }^{18,20}$. The application of coherence provides a valuable analytical tool to investigate functional connectivity between areas or regions and changes that occur due to several factors such as task complexity, context and learning ${ }^{25,26}$. Thus, the increase in gammaband coherence may be seen through an organization of somatotopic information when neural networks are involved parallely in motor execution improvement ${ }^{20}$. This occurs, mainly, due to the projections of the corpus callosum in transmission of sensorimotor information ${ }^{27}$. Concerning our discussion, it is divided into two parts, where we will discuss the significant results for P3-P4 and PZ-OZ pairs of electrodes and their relationship with the gamma band.

Our first result demonstrated a significant difference in gamma coherence between moment preceding and after ball drop for P3-P4 electrodes pair, i.e., an increase in coherence in the moment after ball drop. It seems only in this moment, the CNS was capable to integrate relevant information about the task, the so-called binding phenomena, like a consequence of task demands, i.e., the manipulation of objects, and the visuospatial processing (i.e., spatiotemporal coordination related to the contact hand-object $)^{10,11}$. It is likely that binding occurs in many different kinds of brain processes and may represent a diverse set of functions. In our task, in the moment preceding ball drop, subjects received an amount of sensory stimuli which seemed not to be sufficient to prepare them for catching the ball. In line with this, Pfurtscheller et al. ${ }^{28}$ argued that the sensorimotor system works in idling state for lack of somatosensory information processing or motor response generated, like for lack of visual information processing. Such fact can justify the lower values of coherence during moment preceding ball drop when compared with moment after ball drop.

On the other hand, in the moment after ball drop, our findings suggest that the increase in cortical communication across left and right parietal areas happened due to the visual and somatosensory inputs related to the motor execution. It is knowledge that the control of movement is distributed over neural populations which encode movement-related information, that is, the neural network has to transform the sensory information into an appropriate command for motor system operation ${ }^{29,30}$. With regard to this, somatosensory and visual inputs clearly make an important contribution to location and manipulation of objects, oculomanual coordination and attentional processes ${ }^{10-12}$. We argue that the subjects to maintain an "on-line" control of the task, should integrate somatosensory inputs such as, adjustment of the posture and position of the hand to perform the task ${ }^{31,32}$.
In our task, subjects had to attend to an object (i.e., the ball) while prepared for catching it, requiring a visual guidance for hand movements which need a set of somatosensory inputs to control the movements, more specifically, the manipulation of the ball that involves the synchronous coordination of finger movements ${ }^{14-16}$. Besides, it is necessary adjusting the hand to the shape and to the fall line of the ball (i.e., posture and position of the hand related to the ball). In our task, attention and visuospatial processing regarding the manipulation of the ball ${ }^{10,11}$ vertically dropping occurs in a short space of $40 \mathrm{~cm}$ above the floor, what would justify the activation of parietal areas, despite these movements are faster to allow to subjects to use visual inputs in real-time. In this context, our findings support that parietal areas can direct movements based on sensory information, which is relevant for goal-directed tasks ${ }^{29,30}$, e.g., reaching and grasping a cup.

In relation to our second result, it was found a significant difference in gamma coherence between moment preceding and after ball drop for PZ-OZ electrodes pair, i.e., an increase in coherence in the moment after ball drop. As expected, our hypothesis was confirmed. It might be explained due to the sufficient amount of sensory stimuli provided by task in this moment in contrast to moment preceding ball drop according to the same discussion regarding P3-P4 results ${ }^{28}$. Regarding the moment after ball drop, we thought that a strong integration of only somatosensory inputs happened to adjust and to aid the task execution, however, probably without a markedly participation of the visual inputs (i.e., feedforward mechanism of the motor control system). Our task involves faster movements to allow to subjects to use visual inputs in real-time ${ }^{33}$, suggesting that the available visual information during the fast period of the ball dropping was not sufficient enough to influence on increase in gamma coherence, which would explain we do not find any significant result on O1-O2 electrodes pair. In addition, it has been observed in priming experiments that repeated presentation of the same visual stimulus results in an accommodation of the induced gamma activity $^{34}$. Thus, our task would require a greatest somatosensory demand related to the motor execution by itself (i.e., catching the ball), justifying the activation of the parietooccipital junction.

Within this context, it has been reported that the parietooccipital junction plays a critical role in real-time control of action by transforming the information about the location of objects into the coordinate frames of the effectors performing the action ${ }^{35}$. Evidence suggest that this region is mainly involved in controlling "on-line" actions, in movements of object manipulation and in space perception $^{36,37}$. Thus, parietooccipital is seen as an orga- 
nizer of visual and somatosensory inputs, elaborating them on form, space, and proprioceptive mechanisms suitable for the control of movements ${ }^{35-37}$. Therefore, this process of information organization and their transformation in suitable actions might explain the greater activation of the PZ-OZ electrodes pair, in the moment after ball drop. Thus, in this moment, we argue that happened before the task execution an integration of somatosensory inputs about coordination of the finger movements related to visual target (i.e., spatial attention control and visual representation regarding the ball dropping) ${ }^{38}$ and also an anticipatory coordination of grip and load forces to maintain grasp stability during object manipulation (i.e., postural regularization and in position of the arm during a task) as a basis for the movement organization ${ }^{39}$. That information would be available on an implicit memory elaborated by constant motor execution along the task.

We proposed that gamma plays an important role in reflecting binding of several brain areas in complex motor tasks as observed in our results. We observed that parietal areas and parietooccipital junction played and relevant role, in contrast to visual areas. We conclude that to execute tasks involving anticipatory movements (feedforward mechanisms), like our own task, probably, there is no need of a strong participation of visual areas in the process of information organization to manipulate objects and to process visuospatial information regarding the contact hand-object. At last, we recommend further experiments that use different objects and randomization time and new population, that is, new information necessary to expand the knowledge about gamma and coherence behavior and better understanding the processes involved in cortical functions and in binding problem.

\section{REFERENCES}

1. Vidoni ED, McCarley JS, Edwards JD, Boyd LA. Manual and oculomotor performance develop contemporaneously but independently during continuous tracking. Exp Brain Res 2009;195:611-620.

2. Johansson RS, Westling G, Bäckström A, Flanagan JR. Eye-hand coordination in object manipulation. J Neurosci 2001;21:6917-6932.

3. Crawford JD, Medendorp WP, Marotta JJ. Spatial transformations for eyehand coordination. J Neurophysiol 2004;92:10-19.

4. Liesker H, Brenner E, Smeets J. Combining eye and hand in search is suboptimal. Exp Brain Res 2009;197:395-401.

5. Bowman MC, Johansson RS, Flanagan JR. Eye-hand coordination in a sequential target contact task. Exp Brain Res 2009;195:273-283.

6. Buneo CA, Andersen RA. The posterior parietal cortex: sensorimotor interface for the planning and online control of visually guided movements. Neuropsychologia 2006:44:2594-2606.

7. Battaglia-Mayer A, Archambault PS, Caminiti R. The cortical network for eyehand coordination and its relevance to understanding motor disorders of parietal patients. Neuropsychologia 2006;44:2607-2620.

8. Gomi H. Implicit online corrections in reaching movements. Curr Opin Neurobiol 2008; 18:558-564.

9. Jackson SR, Newport R, Husain M, Fowlie JE. O'Donoghue M, Bajaj N. There may be more to reaching than meets the eye: re-thinking optic ataxia. Neuropsychologia 2009;47:1397-1408.

10. Medendorp WP, Goltz HC, Vilis T, Crawford JD. Gaze-centered updating of visual space in human parietal cortex. J Neurosci 2003;23:6209-6214.

11. Avillac M, Deneve S, Olivier E, Pouget A, Duhamel JR. Reference frames for representing visual and tactile locations in parietal cortex. Nat Neurosci 2005;8:941-949.

12. Giménez-Amaya JM. Anatomía funcional de la corteza cerebral implicada en los procesos visuales. Rev Neurol 2000;30:656-662.

13. Portella CE, Silva JG, Machado S, et al. EEG spectral coherence inter- and intrahemispheric during catching object fall task. Arq Neuropsiquiatr 2007;65:63-67.

14. Nader S, Machado S, Cunha M, et al. Posterior parietal cortex role in a sensorimotor task performance. Arq Neuropsiquiatr 2008;66:341-343.

15. Machado S, Portella CE, Silva JG, et al. Changes in quantitative EEG absolute power during the task of catching an object in free fall. Arq Neuropsiquiatr 2007;65:633-636.

16. Velasques $B$, Machado S, Portella CE, et al. Cortical asymmetry: catching an object in free fall. Arq Neuropsiquiatr 2007;65:623-627.

17. Roskies AL. The binding problem review introduction. Neuron 1999;241:7-9.

18. Herrmann CS, Fründ I, Lens D. Human gamma-band activity: a review of cognitive and behavioral 86 correlates and network models. Neuroci Biobehav Rev 2010;34:981-992.

19. Basar-Eroglu C, Strüber D, Schürmann M, Stadler M, Basar E. Gamma-band response in the brain: a short review of psychophysiological correlates and functional significance. International J Psychophysiol 1996;24:101-112.

20. Szurhaj W, Bourriez JL, Kahane P, Chauvel PM, Mauguie F, Derambure P. Intracerebral study of gamma rhythm reactivity in the sensorimotor cortex. Eur J Neurosci 2005;21:1223-1235.

21. Grosse-Wentrup M, Schölkopf B, Hill J. Causal influence of gamma oscillations on the sensorimotor rhythm. Neuroimage, in press.

22. Dushanova J, Philipova D, Nikolova G. Beta and gamma frequency-range abnormalities in parkinsonian patients under cognitive sensorimotor task. J Neurol Sci 2010;293:51-58.

23. Oldfield R. The assessment and analysis of handedness: the Edinburg Inventory. Neuropsychologia 1971;9:97-113.

24. Jasper $\mathrm{H}$. The ten-twenty electrode system of the international federation. EEG Clin Neurophysiol 1958;10:371-375.

25. Serrien DJ, Spapé MM. Effects of task complexity and sensory conflict on goal-directed movement. Neurosci Lett 2009;464:10-13.

26. Deeny SP, Haufler AJ, Mark S, Hatfield BD. Eletroencephalographic coherence during visuomotor performance. A comparasion of cortico cortical communication in experts and novices. J Motor Behav 2009;41:106-116.

27. Liepert J, Dettmers C, Terborg C, Weiller C. Inhibition of ipsilateral motor cortex during phasic generation of low force. Clin Neurophysiol 2001; 112:114-121.

28. Pfurtscheller G, Neuper C, Andrew C, Edlinger G. Foot and hand mu rhythms. Internat J Psychophysiol 1997;26:121-135.

29. Ghafouri M, Mcllroy WE, Maki BE. Initiation of rapid reach-and-grasp balance reactions: is a pre-formed visuospatial map used in controlling the initial arm trajectory? Exp Brain Res 2004;155:532-536.

30. Prablanc C, Desmurget M, Gréa H. Neural control of on-line guidance of hand reaching movements. Prog Brain Res 2003;142:155-170.

31. Corbetta M, Miezin FM, Shulman GL, Petersen SE. A PET study of visuospatial attention. J Neurosci 1993;13:1202-1226.

32. Mesulam MM. Spatial attention and neglect: parietal, frontal and cingulate contributions to the mental representation and attentional targeting of salient extrapersonal events. Philos Trans R Soc Lond B Sci 1999;354: 1325-1346.

33. Bagesteiro LB, Sainburg RL. Nondominant arm advantages in load compensation during rapid elbow joint movements. J Neurophysiol 2003;90: 1503-1513.

34. Gruber T, Muller MM. Effects of picture repetition on induced gamma band responses, evoked potentials, and phase synchrony in the human EEG. Brain Res Cogn Brain Res 2002;13:377-392.

35. Goodale MA, Milner AD. Separate visual pathways for perception and action. Trends Neurosci 1992;15:20-25.

36. Galletti C, Kutz DF, Gamberini M, Breveglieri R, Fattori P. Role of the medial parieto-occipital cortex in the control of reaching and grasping movements. Exp Brain Res 2003;153:158-170.

37. Rizzolatti G, Matelli M. Two different streams from the dorsal visual system: anatomy and functions, Exp Brain Res 2003;153:146-157.

38. Ramnani N, Toni I, Passingham RE, Haggard P. The cerebellum and parietal cortex play a specific role in coordination: a PET study. Neuroimage 2001;14:899-911.

39. Ehrsson HH, Fagergren A, Johansson RS, Forssberg H. Evidence for the involvement of the posterior parietal cortex in coordination of fingertip forces for grasp stability in manipulation. J Neurophysiol 2003;90: 2978-2986. 